\title{
Indicadores de desempenho relacionado ao parto de fêmeas suínas de primeiro e segundo partos
}

\author{
Ivan Bianchi ${ }^{1}$, Thomaz Lucia Junior ${ }^{1}$, João Carlos Deschamps ${ }^{1}$, Augusto Schneider ${ }^{1}$, Viviane \\ Rohrig Rabassa ${ }^{1}$, Marcio Nunes Corrêa ${ }^{1}$

\begin{abstract}
${ }^{1}$ NUPEEC - Núcleo de Pesquisa, Ensino e Extensão em Pecuária. Faculdade de Veterinária, Universidade Federal de Pelotas, Pelotas, RS, CEP: 96010-900.
\end{abstract}

RESUMO - Foi realizado um estudo para identificar parâmetros de desempenho associados a indicadores de eficiência durante o parto de fêmeas suínas. Foram coletados os seguintes dados de 636 partos e 7.100 leitões nascidos: ordem de parto, número de leitões nascidos vivos, natimortos, mumificados, total de nascidos, aplicação de ocitocina, uso de palpação vaginal, momento do nascimento de cada leitão e do início e final do parto. O intervalo médio de nascimento dos leitões foi de 16,7 minutos e a duração média do parto, de 247 minutos. A duração média do parto aumentou conforme o total de leitões nascidos, o uso de ocitocina e a ocorrência de palpação vaginal. O total de nascimentos nos partos longos ( $\geq 211$ min), de 13,1 leitões, foi maior que nos partos curtos ( $\leq 210 \mathrm{~min}$ ), de 11,7 leitões, portanto, quanto maior o total de nascidos, maior a duração do parto. As leitegadas foram maiores nas fêmeas de segundo parto $(12,8)$ em comparação àquelas de primeiro parto $(11,9)$. A duração do parto é influenciada pelo total de leitões nascidos, que é maior em fêmeas de segundo parto e está associada à maior ocorrência de leitões natimortos e mumificados.

Palavras-chave: leitegada, ordem de parto, suínos

\section{Performance parameters linked to the parturition of first and second parturition sows}

\begin{abstract}
This study aimed to identify some performance parameters associated with the farrowing efficiency in sows. From a total of 636 births and 7,100 piglets born, data was collected for: parity (OP), number of piglets born alive (NV), stillborns (NAT), mummified (MUM), total litter size (TN), use of vaginal palpation and oxytocin injection, time of birth for each piglet, and beginning and end of the parturition. The average interval among piglets birth was 16.7 min and the average duration of parturition was $247 \mathrm{~min}$. The average duration of parturition increased regarded to the number of born piglets, the use of oxytocin and with the ocurence of vaginal palpation. The total number of births in the long parturitions ( $\geq 211 \mathrm{~min}$ ), with 13.1 piglets was higher than in the short parturitions ( $\leq 210 \mathrm{~min}$ ), with 11.7 piglets, therefore, the higher the number of total piglets born, the longer is the duration of parturition. Litter size was higher for sows of the second parity (12.8) than for sows of first parity (11.9). The duration of parturition is affected by the number of piglets born, which is higher in second parity than first parity females and it is associated to the higher occurence of stillbirths and mummified piglets.
\end{abstract}

Key Words: litter, parity, swine

\section{Introdução}

Nos sistemas de produção intensiva de suínos, é fundamental proceder à coleta e ao registro criteriosos dos dados de desempenho zootécnico para a correta interpretação dos índices obtidos e identificação dos pontos críticos relacionados ao desempenho inadequado nas granjas (Araújo et al., 2009). Isso poderá permitir o planejamento de estratégias de manejo adequadas (Muirhead \& Alexander, 1997).
O acompanhamento do parto pode ser fundamental para assegurar a lucratividade do setor suinícola, pois, a partir de práticas corretas de manejo durante o parto, tem-se garantido a viabilidade da leitegada e assegurado boas condições de saúde das matrizes. Há registros de que a duração média do parto é de 3 horas (180 min) para um número médio de 11,7 leitões nascidos, com intervalo de 15 a 20 min entre a expulsão de cada leitão (Cutler et al., 1999). Se a duração do parto aumentar de 3 para 8 horas, a porcentagem de leitegadas com natimortos pode aumentar

Recebido em 20/5/2008 e recebido em 18/5/2009. 
de 18 para 61\% (Britt et al., 1999). A avaliação do intervalo de nascimento dos leitões pode determinar o momento ou a necessidade de intervenção e auxílio ao parto, seja pelo uso de ocitocina, seja por palpação vaginal ou cesariana (Cutler et al., 1999). A intervenção inapropriada pode comprometer a viabilidade do leitão nos casos de partos distócicos, aumentando o risco de leitões natimortos por anoxia(Santoro etal., 2003; Herpin etal., 2001; Lucia etal., 2002). Além disso, pode ocorrer aumento no descarte de fêmeas que foram mal manejadas pela indução do parto ou palpação vaginal, reduzindo a vida útil da fêmea no plantel, o que pode contribuir para o aumento do número de dias nãoprodutivos e para a concomitante redução da eficiência reprodutiva (Cutler et al., 1999; Lucia et al., 2000).

Dessa forma, o momento e a forma de intervir ou auxiliar o parto remetem a uma decisão que deve ser baseada em critérios técnicos bem estabelecidos pela equipe do setor de maternidade, de maneira a assegurar a saúde do leitão e da fêmea. Assim, é necessário avaliar os indicadores de desempenho zootécnico relacionados ao momento do primeiro e segundo partos de fêmeas suínas.

\section{Material e Métodos}

Este trabalho foi realizado entre os meses de fevereiro e outubro em uma granja multiplicadora localizada na região sul do Rio Grande do Sul. Foi realizada a coleta de dados de desempenho zootécnico de 636 partos de fêmeas de raças puras (548 Landrace e 88 Large White), que originaram um total de 7.100 leitões.

A coleta de dados foi realizada 24 horas por dia, com o registro em cada parto, do número de leitões nascidos vivos, natimortos, mumificados e do total de nascidos. Também foi registrado o momento do início e do final do parto, a fim de obter a duração total do parto. Durante o trabalho de parto, verificou-se o número total de intervenções realizadas, que poderia ser por aplicação de ocitocina ou pelo uso de palpação vaginal nos partos diagnosticados como distócicos. Foi considerado distócico o parto cujo intervalo de nascimento dos leitões ultrapassou 30 minutos (Cutler et al., 1999). Para cada leitão nascido foram registrados a ordem e o momento do nascimento (hora) com o objetivo de determinar o intervalo de nascimento dos leitões, em minutos.

A coleta dos dados foi realizada pela equipe do setor de maternidade da granja, composta de cinco funcionários além de um chefe de setor, treinados previamente pelo médico veterinário responsável da granja. O treinamento consistiu da padronização do manejo de atendimento ao parto e preenchimento das fichas de coleta de dados. Os dados de ordem de parto das fêmeas incluídas no trabalho foram extraídos dos relatórios do banco de dados da granja (PigWIN $\left.{ }^{\circledR}, 2001\right)$.

A partir da distribuição de frequências, foram categorizados o intervalo de nascimento dos leitões e a duração do parto. O intervalo de nascimento dos leitões foi categorizado em $\leq 10 \mathrm{~min}, 11$ a 20,21 a 30, 31 a 40 e $\geq 41$ min e a duração do parto, em $\leq 180$ min, 181 a 210, 211 a 240, 241 a 270, 271 a 300 e $\geq 301 \mathrm{~min}$. Estas duas variáveis foram também avaliadas segundo a ordem de parto. Adicionalmente, para verificar seu impacto nos índices zootécnicos, a duração do parto foi novamente categorizada em: normal ( $\leq 210 \mathrm{~min})$ e longa ( $\geq 211 \mathrm{~min})$. Para efeitos de análise, o total de leitões nascidos e o número de nascidos vivos foi categorizado em: $\leq 9,10-11 \mathrm{e} \geq 12$.

A análise de variância foi realizada considerando como variáveis dependentes o intervalo de nascimento dos leitões, a duração do parto e o total de leitões nascidos e como variáveis independentes a ordem de parto, a duração do parto categorizada (normal ou longa), o total de leitões nascidos e o número de nascidos vivos (categorizados) e a ocorrência ou não de natimorto, feto mumificado, de palpação vaginal durante o parto e de aplicação de ocitocina durante o parto. Possíveis interações entre as variáveis independentes foram testadas. As comparações entre médias foram feitas pelo teste LSD. Todas as análises foram realizadas pelo programa Statistix ${ }^{\circledR}$ (2004).

\section{Resultados e Discussão}

O intervalo médio de nascimento dos 7.100 leitões foi de 16,7 minutos. Foram analisados 417 partos de fêmeas de primeiro parto, que totalizaram 4.621 leitões nascidos (média de 11,9 $\pm 0,1$ leitões/parto) e 219 partos de segundo parto, totalizando 2.479 leitões nascidos (média de 12,8 \pm 0,2 leitões/parto). As médias de leitões nascidos nas fêmeas de primeiro e de segundo parto foram diferentes $(\mathrm{P}<0,05)$ entre si.

A ocorrência de distocia é frequente em fêmeas primíparas, assim como em fêmeas velhas (7 ou mais partos), cursando com o aumento do intervalo de nascimento dos leitões, com o prolongamento do parto e com aumento do risco de natimortos (Cutler et al., 1999). O tempo médio entre o nascimento de leitões neste estudo está de acordo com valores encontrados por outros autores para granjas comerciais no Brasil (Borges et al., 2005). Além disso, mesmo trabalhando somente com fêmeas de primeiro e segundo parto, o intervalo médio de nascimento dos leitões, independentemente da ordem de parto, foi menor ou igual a $20 \mathrm{~min}$, considerado adequado para essas categorias (Cutler et al., 1999). No entanto, para atingir 
esta meta, é necessário respeitar as indicações de idade e peso mínimo para a primeira cobertura ou inseminação artificial, além de um adequado manejo de arraçoamento a fim de que a fêmea esteja em boa condição corporal ao final da gestação, evitando distocias no momento do parto.

A duração média do parto foi de $247 \pm 78$ minutos, superior ao tempo de 180 minutos, esperado para fêmeas suínas (Plonait, 1988). No entanto, as linhagens de fêmeas dos atuais sistemas de produção possuem maior produtividade, o que explica a maior duração do parto. Os resultados são de fêmeas de primeiro e segundo partos, que naturalmente possuem a duração média do parto mais prolongada, por serem mais jovens (Cutler et al., 1999), pois os estágios do parto, relacionados à contratilidade do miométrio e dilatação da cérvix (estágio 1) e à expulsão do feto (estágio 2), não são tão eficientes na fêmea jovem como nas fêmeas adultas (Senger, 2003).

De acordo com a avaliação da duração do parto, quanto maior o número de leitões nascidos, mais longo o parto ( $\mathrm{P}<0,001)$, podendo chegar a mais de 4 horas (240 minutos) em leitegadas com 10 ou mais leitões (Tabela 1 ). Trabalhos comprovam que leitegadas numerosas estão associadas a leitões de baixo peso ao nascer e a partos de longa duração, o que aumenta o risco de natimortos (Dial et al., 1992; Muirhead \& Alexander, 1997).

Tabela 1 - Duração média do parto avaliada de acordo com o total de leitões nascidos, a aplicação de ocitocina e com o uso de palpação vaginal

\begin{tabular}{lccc}
\hline Item & & $\begin{array}{c}\text { Total de } \\
\text { partos (n) }\end{array}$ & $\begin{array}{c}\text { Duração do } \\
\text { parto } \\
\text { (minutos) }\end{array}$ \\
\hline Total de leitões nascidos & $\geq 12$ & 317 & $257,5 \pm 3,8 \mathrm{a}$ \\
& $10-11$ & 154 & $249,4 \pm 5,4 \mathrm{a}$ \\
Aplicação de ocitocina & $\leq 9$ & 165 & $179,2 \pm 5,3 \mathrm{~b}$ \\
& Sim & 579 & $253,2 \pm 2,8 \mathrm{a}$ \\
Palpação vaginal & $\mathrm{Não}$ & 57 & $204,2 \pm 8,9 \mathrm{~b}$ \\
& Sim & 133 & $256,6 \pm 5,9 \mathrm{a}$ \\
a, b - Médias com letras diferentes na mesma coluna diferem $(\mathrm{P}<0,001)$ para cada \\
item.
\end{tabular}

A duração do parto foi maior quando houve a necessidade de intervenção com aplicação de ocitocina (253,2 × 204,2 min, $\mathrm{P}<0,001)$ ou com palpação vaginal (256,6 × 200,8 minutos, $\mathrm{P}<0$,001) (Tabela 1). Como relatado por Cutler et al. (1999), fêmeas jovens têm maior risco de intervenção obstétrica. Dessa forma, a duração mais prolongada do parto em fêmeas que receberam auxílio obstétrico, pelo uso de ocitocina ou palpação vaginal, foi confirmada segundo os procedimentos de diagnóstico de distocia de parto, conforme descrito por Runnels \& Clark (1992).

Em partos de leitegadas com mais de dez leitões e que necessitaram intervenção, seja por palpação vaginal seja por aplicação de ocitocina, houve prolongamento da duração $(\mathrm{P}<0,05)$ de pelo menos 50 minutos em relação àqueles que dispensaram intervenção (Tabela 2). Esse resultado confirma a importância do correto manejo de atendimento ao parto na redução do estresse de fêmeas com distocia e na garantia do bem-estar da fêmea e da sobrevivência dos leitões. Conforme destacado por Runnels \& Clark (1992), manobras obstétricas, como a palpação vaginal, devem ser usadas somente após correto diagnóstico de sua necessidade em casos de distocia, e não apenas para se certificar de que não há mais leitões para nascer.

Quanto maior o tamanho da leitegada mais prolongado foi o parto (13,1 leitões, $\geq 211 \mathrm{~min} \times 11$,7 leitões, $\leq 210 \mathrm{~min}$; $\mathrm{P}<0,05)$. Partos com leitegadas mais numerosas resultaram em mais leitões natimortos e mumificados $(\mathrm{P}<0,05)$ (Tabela 3). O efeito do tamanho da leitegada na duração do parto e na ocorrência de natimortos e mumificados foi descrito por outros autores (Plonait, 1988; Britt et al., 1999) e provavelmente está relacionado à maior duração do parto em leitegadas numerosas, o que eleva a probabilidade de ocorrência de natimortos, assim como leitegadas numerosas aumentam a probabilidade de ocorrência de leitões mumificados, que podem dificultar o parto e aumentar sua duração. Além disso, partos com leitões

Tabela 2 - Duração média do parto avaliada de acordo com o total de nascidos e com o uso de palpação vaginal

\begin{tabular}{|c|c|c|c|c|c|}
\hline Item & & & & $\begin{array}{c}\text { Total } \\
\text { de partos (n) }\end{array}$ & $\begin{array}{c}\text { Duração } \\
\text { (minutos) }\end{array}$ \\
\hline \multirow[t]{2}{*}{ Total de leitões nascidos } & $\geq 12$ & Palpação vaginal & Sim & 54 & $292,2 \pm 9,2 \mathrm{a}$ \\
\hline & & & Não & 263 & $222,9 \pm 4,2 b$ \\
\hline \multirow[t]{2}{*}{ Total de leitões nascidos } & $10-11$ & Palpação vaginal & Sim & 28 & $282,3 \pm 12,8 a$ \\
\hline & & & Não & 126 & $216,4 \pm 6,0 \mathrm{bc}$ \\
\hline \multirow[t]{2}{*}{ Total de leitões nascidos } & $\leq 9$ & Palpação vaginal & Sim & 51 & $195,3 \pm 9,5 c$ \\
\hline & & & Não & 114 & $163,1 \pm 6,3 d$ \\
\hline
\end{tabular}

a, b, c, d - Médias com letras diferentes na mesma coluna diferem $(\mathrm{P}<0,05)$ para cada item. 
mumificados, independentemente da ordem de parto da mãe (Tabela 4), foram indicativos de leitegada numerosa $(\mathrm{P}<0,05)$, porém esta ocorrência foi maior $(\mathrm{P}<0,05)$ nas fêmeas de segundo parto.

Fêmeas de segundo parto tiveram leitegadas maiores $(12,8)$ em relação às fêmeas de primeiro parto $(11,9 ; \mathrm{P}<0,05)$, o que confirma os realtos de Borges et al. (2005), de que fêmeas de ordem de parto 2 a 5 são mais prolíferas que aquelas de primeiro parto. A média de leitões nascidos deve ser considerada satisfatória, especialmente por se tratarem de fêmeas de primeiro e segundo partos (Coma et al., 1996; Fonseca et al., 2000; Yang et al., 2000).

Tabela 3 - Total de leitões nascidos em fêmeas suínas de primeiro e segundo partos

\begin{tabular}{|c|c|c|c|}
\hline \multicolumn{2}{|l|}{ Item } & \multirow[t]{2}{*}{$\begin{array}{l}\text { Total de } \\
\text { partos (n) }\end{array}$} & \multirow[t]{2}{*}{ Média \pm EP } \\
\hline $\begin{array}{l}\text { Duração do parto } \\
\text { (minutos) }\end{array}$ & $>211$ & & \\
\hline & $\leq 210$ & 214 & $11,7 \pm 0,2 b$ \\
\hline \multirow[t]{2}{*}{ Natimortos } & Sim & 218 & $13,1 \pm 0,2 \mathrm{a}$ \\
\hline & Não & 418 & $11,6 \pm 0,1 b$ \\
\hline \multirow[t]{2}{*}{ Mumificados } & Sim & 98 & $13,3 \pm 0,3 a$ \\
\hline & Não & 538 & $11,4 \pm 0,1 b$ \\
\hline \multirow[t]{2}{*}{ Ordem de parto } & 2 & 219 & $12,8 \pm 0,2 \mathrm{a}$ \\
\hline & 1 & 417 & $11,9 \pm 0,1 b$ \\
\hline
\end{tabular}

a, b - Médias com letras diferentes na mesma coluna diferem $(\mathrm{P}<0,05)$ para cada item.

Tabela 4 - Total de leitões nascidos em fêmeas suínas de primeiro e segundo partos

\begin{tabular}{lccc}
\hline Presença de mumificado & $\begin{array}{c}\text { Ordem de } \\
\text { parto }\end{array}$ & $\begin{array}{c}\text { Total de } \\
\text { partos }(\mathrm{n})\end{array}$ & Média \pm EP \\
\hline Sim & 2 & 32 & $14,2 \pm 0,5 \mathrm{a}$ \\
Sim & 1 & 66 & $12,5 \pm 0,4 \mathrm{~b}$ \\
Não & 2 & 187 & $11,4 \pm 0,2 \mathrm{c}$ \\
Não & 1 & 351 & $11,4 \pm 0,2 \mathrm{c}$ \\
\hline
\end{tabular}

a, b, c - Letras diferentes na coluna diferem $(P<0,05)$ para cada item.

\section{Conclusões}

A duração do parto é influenciada pelo total de leitões nascidos, que é maior em fêmeas de segundo parto e está associada à maior ocorrência de leitões natimortos e mumificados.

\section{Referências}

ARAÚJO, É.B.; COSTA, E.P.; COSTA, A.H.A. et al. Reproductive performance of sows submitted to intrauterine insemination. Revista Brasileira de Zootecnia, v.38, p.1460-1467, 2009.

BORGES, V.F.; BERNARDI, M.L.; BORTOLOZZO, F.P. et al. Risk factors for stillbirth and foetal mummification in four Brazilian swine herds. Preventive Veterinary Medicine, v.70, p.165-176, 2005.

BRITT, J.H.; ALMOND, G.W.; FLOWERS, W.L. Diseases of the Reproductive System. In: STRAW, B.E.; D'ALLAIRE, S.; MENGELING, W.L. et al. (Eds.) Diseases of swine. 8.ed. Ames: Iowa State University Press, 1999. p.883-911.

COMA, J.; ZIMMERMAN, D.R.; CARRION, D. Lysine requirement of the lactating sow determined by using plasma urea nitrogen as a rapid response criterion. Journal of Animal Science, v.74, p.1056-1062, 1996.

CUTLER, R.S.; FAHY, V.A.; SPICER, E.M. et al. Preweaning Mortality In: STRAW, B.E.; D’ALLAIRE, S.; MENGELING, W.L. et al. (Eds.) Diseases of swine. 8.ed. Ames: Iowa State University Press, 1999. p.985-1001.

DIAL, G.D.; MARSH, W.E.; POLSON, D.D. et al. Reproductive failure: differential diagnosis. In: LEMAN, A.D.; STRAW, B.E.; MENGELING, W.L. et al. (Eds.) Diseases of swine. 7.ed. Ames: Iowa State University Press, 1992. p.88-137.

FONSECA, R.; PIRES, A.V.; LOPES, P.S. et al. Estudo da divergência genética entre raças suínas utilizando técnicas de análise multivariada. Arquivo Brasileiro de Medicina Veterinária e Zootecnia, v.52, p.403-409, 2000.

HERPIN, P.; HULIN, J.C.; LE DIVIDICH, J. et al. Effect of oxygen inhalation at birth on the reduction of early postnatal mortality in pigs. Journal of Animal Science, v.79, p.5-10, 2001.

LUCIA JR., T.; CORRÊA, M.N.; DESCHAMPS, J.C. et al. Risk factors for stillbirths in two swine farms in the south of Brazil. Preventive Veterinary Medicine, v.53, p.285-292, 2002.

LUCIA JR., T.; DIAL, G.D.; MARSH, W.E. Lifetime reproductive performance in female pigs having distinct reasons for removal. Livestock Production Science, v.63, p.213-222, 2000.

MUIRHEAD, M.R.; ALEXANDER, T.J.L. Managing pig health and the treatment of disease. A reference for the farm. United Kingdom: 5M Enterprises, Sheffield, 1997. 610p.

PIGWIN ${ }^{\circledR}$ [2001]. PigWIN ${ }^{\circledR}$ Version 1.9 FarmWise Systems Inc. Disponível em: <http://www.pigwin.com/> Acesso em: 19/5/2010.

PLONAIT, H. Geburt, puerperium und perinatale verluste. In: PLONAIT, H.; BICKHARDT, K. (Eds.) Lehrbuch der Schweine-Krankheiten. Berlin: Paul Parey, 1988. p.309-339.

RUNNELS, L.J.; CLARK, L.K. Obstetrics. In: LEMAN, A.D.; STRAW, B.E.; MENGELING, W.L. et al. (Eds.) Diseases of swine. 7.ed. Ames: Iowa State University Press, 1992. p.925-932.

SANTORO, K.R.; BARBOSA, SEVERINO, B.P. et al. Modelos de predição da natimortalidade em suínos. Revista Brasileira de Zootecnia, v.32, p.1131-1140, 2003.

SENGER, P.L. Placentation, the endocrinology of gestation and parturition. In: SENGER, P.L. (Ed.) Pathways to pregnancy and parturition. 2.ed. Washington: Current Conceptions, 2003. p.304-325.

STATISTIX ${ }^{\circledR}$ [2004]. Statistix for Windows. Tallahassee: Analytical Software. Disponível em: <http://www.statistix.com> Acesso em: 19/5/2010.

YANG, H.; PETTIGREW, J.E.; JOHNSTON, L.J. et al. Lactational and subsequent reproductive responses of lactating sows to dietary lysine (protein) concentration. Journal of Animal Science, v.78, p.348-357, 2000. 